\title{
COMPARISON OF INSULIN GLARGINE WITH HUMAN PREMIX INSULIN IN PATIENTS WITH TYPE 2 DIABETES INADEQUATELY CONTROLLED ON ORAL HYPOGLYCEMIC DRUGS IN A 24-WEEK RANDOMIZED STUDY AMONG INDIAN POPULATION
}

Abhishek Singhai, Subodh Banzal, Dolly Joseph, Rajesh Kumar Jha, Pragya Jain

1. Assistant Professor, Department of Medicine, Sri Aurobindo Medical College \& PG Institute, Indore, India.

2. Associate Professor, Department of Endocrinology, Sri Aurobindo Medical College \& PG Institute, Indore, India.

3. Associate Professor, Department of Medicine, Sri Aurobindo Medical College \& PG Institute, Indore, India.

4. Professor \& Head, Department of Medicine, Sri Aurobindo Medical College \& PG Institute, Indore, India.

5. DOMS, Department of Opthalmology, Sri Aurobindo Medical College \& PG Institute, Indore, India.

\section{CORRESPONDING AUTHOR}

Dr. Abhishek Singhai, MD Medicine, Assistant Professor, Department of Medicine,

Sri Aurobindo Medical College \& PG Institute, Indore, India

E-mail: drabhisheksinghai@gmail.com

Ph: 00919926597070.

ABSTRACT: INTRODUCTION: Type 2 diabetes is a progressive disorder of $\beta$-cell dysfunction. Patients using oral therapy alone for it seldom achieve and maintain the recommended $7 \%$ HbA1c goal for glycemic control. However, the majority of patients with a longer duration of diabetes remain poorly controlled with oral agents, and use of insulin, which could improve glycemic control, is often long delayed and not aggressive enough. Glargine, a long-acting insulin analog with a more favourable 24-h time-action profile (no pronounced peak) than long- or intermediate-acting human insulin preparations, may be especially suited in this condition. AIMS: To compare the safety and efficacy of the long-acting analog insulin glargine and human premix insulin in patients with type 2 diabetes who were previously treated with oral hypoglycemic drugs alone but inadequately controlled. SETTINGS AND DESIGN: A total of 750 subjects with type 2 diabetes who were receiving oral hypoglycemic drugs for diabetes control were randomized to receive insulin glargine once daily $(\mathrm{n}=370)$ or human premix insulin twice daily $(n=380)$ for 24 weeks in an open-label, tertiary centre study. Doses were adjusted systematically to obtain target fasting glucose $<100 \mathrm{mg} / \mathrm{dl}$. Outcomes included fasting blood sugar, HbA1c levels, change in weight and insulin dose from study start to end. STATISTICAL ANALYSIS: Qualitative variables were tested using Chi square test and $\mathrm{p}$ values were calculated between two groups. RESULTS: At the start of study, age range was 30-70 years, BMI was 26.48 +/- $6.3 \mathrm{~kg} / \mathrm{m}^{(2)}$, and HbA1c was $11.9+/-3.1 \%$ (mean +/- SD) for both group. The mean change (means $\pm \mathrm{SD}$ ) in HbA1c from baseline to end point was similar in the insulin glargine group $(-3.0 \pm 1.68 \%)$ and the human premix insulin group $(-2.89 \pm 1.79 \%)$ (P value $=0.3861)$. The symptomatic hypoglycemic episodes were greater with human premix insulin than with glargine (significance level 0.00002).Subjects in the insulin glargine group experienced less weight gain than those in the premix human insulin group (0.4 vs. $1.4 \mathrm{~kg}, \mathrm{P}<0.0001)$. CONCLUSIONS: In patients with type 2 diabetes, once-daily bedtime insulin glargine is as effective as twice-daily human premix insulin in improving and maintaining glycemia control. In addition, insulin glargine demonstrates a lower risk of symptomatic hypoglycemia and less weight gain compared with human premix insulin. The treatments were associated with similar reductions in fasting glucose levels and $\mathrm{HbA1c}$ levels. 
KEY-WORDS: Type 2 Diabetes, Glargine, Insulin, Oral hypoglycemic drugs, premix insulin

INTRODUCTION: Type 2 diabetes is a progressive disorder of $\beta$-cell dysfunction. Patients using oral therapy for it seldom achieve and maintain the recommended $7 \% \mathrm{HbA1c}$ goal for glycemic control ${ }^{(1,2)}$ and are exposed to increasing risks of diabetic complications as control worsens over time ${ }^{(3,4)}$.

However, the majority of patients with a longer duration of diabetes remain poorly controlled with oral agents, and use of insulin, which could improve glycemic control, is often long delayed and not aggressive enough. The reluctance to initiate insulin therapy seems partly due to its perceived complexity, and fear of hypoglycemia, which may be the greatest barrier (5).

A regimen that may make initiation of insulin simpler and more effective has been tested in several small studies (6-8). A single bedtime injection of long-acting (basal) insulin is added while prior oral agents are continued, and insulin is systematically titrated, seeking a defined fasting glucose target. Glargine, a long-acting insulin analog with a more favourable 24$\mathrm{h}$ time-action profile (no pronounced peak) than long- or intermediate-acting human insulin preparations (9-10), may be especially suited to this regimen. We compared the abilities of glargine and human premix insulin to reduce HbA1c to $7 \%$ when added to ongoing oral therapy and the hypoglycemia accompanying this effort using a simple algorithm for insulin dosage titration seeking fasting blood glucose (FBG) target of $100 \mathrm{mg} / \mathrm{dl}$.

SUBJECTS AND METHODS: Enrolled subjects were men or women aged 30-70 years, with type 2 diabetes, and treated with stable doses of one or more oral hypoglycemic drugs (sulfonylurea, metformin or pioglitazone) for $\geq 6$ months. There were no significant differences in the mean age, racial distribution, BMI, admission blood glucose, or HbA1c between treatment groups (Table 1). Inclusion criteria included BMI between 26 and $40 \mathrm{~kg} / \mathrm{m}^{2}$, HbA1c more than 7.5, and FBG $\geq 140 \mathrm{mg} / \mathrm{dl}$ at screening. Exclusion criteria included prior use of insulin, current use of an $\alpha$-glucosidase inhibitor or a rapid-acting insulin secretagogue, use of other agents affecting glycaemic control (including systemic glucocorticoids, nonselective $\beta$-sympathetic blockers, and anti obesity drugs), history of ketoacidosis or self-reported inability to recognize hypoglycemia, or serum creatinine ( $\geq 1.5 \mathrm{mg} / \mathrm{dl}$ for men and $\geq 1.4 \mathrm{mg} / \mathrm{dl}$ for women), and a history of drug or alcohol abuse.

This single centre, randomized, parallel, 24-week comparative study was performed at Sri Aurobindo Medical College, Indore between January 2009 and September 2012. Written informed consent has been taken from subjects prior to study.

Patients were randomized to either glargine (Lantus; Aventis) or human premix insulin (mixture of $30 \%$ neutral soluble insulin and $70 \%$ isophane insulin) to be administered subcutaneously at bedtime (glargine) or twice a day (human premix insulin), using a pen injector or insulin syringe as preferred by patient for 24 weeks. Oral hypoglycemic drugs were continued at similar dosages. The starting dose of glargine insulin was $10 \mathrm{IU} /$ day, and dosage was titrated weekly according to laboratory blood glucose levels or self-monitored capillary fasting blood glucose measurements using meters (Accu-Chek Advantage; Roche Diagnostics) that provide values corresponding closely to laboratory measurements of plasma glucose. Dosages titrated till target FBG of $\leq 100 \mathrm{mg} / \mathrm{dl}$ achieved. (Table 2)

Subjects visited centre at baseline and 1,3,5,7,10,12,18 and 24 weeks and contacted telephonically on 2, 4,6,8,9,11,13,14,20 and 22 weeks. Glucose values and insulin changes were recorded each time. Subjects were asked to test glucose whenever they experienced symptoms 
that might be related to hypoglycemia and to record the results. Subjects documenting hypoglycemia by glucose levels $\leq 70 \mathrm{mg} / \mathrm{dl}$ were asked to reduce insulin dose by 2 units. Insulin titration started after one week if symptoms of hypoglycemia did not recur. Weight was measured, and venous blood for FPG was collected between 0800 and $0900 \mathrm{~h}$ at each visit. Blood for HbA1cwas collected at baseline and 12 and 24 weeks. Qualitative variables were tested using Chi square test and $\mathrm{p}$ values were calculated between two groups. $p$ value of $\leq 0.05$ was considered statistically significant. Averages were expressed between groups as mean \pm standard deviation or percentage.

RESULTS: Out of 750 patients screened, 370 were treated with glargine and 380 with human premix insulin. A total of 5 insulin glargine recipients and 15 human premix insulin recipients withdrew from the study after beginning treatment. In 3 insulin glargine subjects and 9 human premix insulin subjects, the reason was the subject's desire to discontinue or loss to follow-up. Two insulin glargine subjects $(0.54 \%)$ and six human premix insulin subjects $(1.57 \%)$ discontinued treatment because of adverse events.

Figure-A illustrates that the mean improvements in HbA1c were similar: $-3.00 \pm 1.68 \%$ for glargine and $-2.89 \pm 1.79 \%$ for human premix insulin $(\mathrm{P}=0.3861)$. The proportions of patients achieving $\mathrm{HbA1c}<7 \%$ were also similar (76.3 and $75.5 \%$, respectively), but fewer human premix insulin than glargine-treated patients reached HbA1c $<6.5 \%$ (14.6 and 26.7\%, respectively).

Change in FBG from baseline was significant at end point in both groups $(\mathrm{P}<0.0001)$. Similar proportions of subjects receiving insulin glargine $(29.6 \%)$ and NPH (27.1\%) achieved FBG $<90 \mathrm{mg} / \mathrm{dl}$ by study end point. (Figure B).

Risk of hypoglycemia was significantly higher with human premix insulin. We found that subjects in the insulin glargine group had 12 episodes of hypoglycemia documented by a blood glucose value $<70 \mathrm{mg} / \mathrm{dl}$, compared with subjects in the human premix insulin group who reported 42 episodes (significance level 0.00002).

Weight gain was significantly higher with human premix insulin versus glargine: $1.4 \pm$ 0.02 and $0.4 \pm 0.012 \mathrm{~kg}(\mathrm{P}<0.0001)$. Average glargine insulin dose was $0.26 \mathrm{IU} / \mathrm{kg}$ and average human premix insulin dose was $0.64 \mathrm{IU} / \mathrm{kg}$ (Figure $\mathrm{C}$ ).

DISCUSSION: Insulin glargine was developed as improved long-acting, basal insulin. It is an analogue of human insulin that is produced in a non-pathogenic strain of Escherichia coli. Insulin glargine differs from human insulin by the addition of two arginine amino acids to the Cterminus of the B-chain and the replacement of asparagine at position A21 by glycine. These changes shift the isoelectric point so that the molecule is soluble at an acid $\mathrm{pH}$, but less soluble at neutral physiological pH levels. This results in a clear solution $(\mathrm{pH} 4.0)$ that when injected forms a precipitate in the subcutaneous tissue, which delays absorption and prolongs duration of action (11). The absorption characteristics of insulin glargine are not affected by the site of injection (arm, leg, or abdominal regions). Furthermore, compared with NPH insulin, the absorption rate is significantly slower with approximately $50 \%$ of the injected dose of insulin glargine still detectable after 24 hours compared with approximately $20 \%$ of the NPH insulin dose (12).

A potential major advantage of insulin glargine over NPH insulin and ultralente preparations is a lack of pronounced peaks in plasma insulin concentrations and a more constant delivery of insulin over a 24 hour period. This smooth profile was clearly shown in 
studies of insulin glargine versus NPH insulin in healthy volunteers and of insulin glargine versus NPH and ultralente insulin in patients with type 1 diabetes $(13,14)$. In fact, in this later study, the delayed absorption of insulin glargine provided a consistent delivery of insulin that closely mimicked insulin delivery by continuous subcutaneous insulin infusion (CSII). Furthermore, in this study, interindividual variability in plasma insulin concentrations was lower with insulin glargine than with NPH or ultralente. These pharmacokinetic studies highlight the potential of insulin glargine to be improved basal insulin for patients with diabetes.

Riddle et al (2003) compared the addition of either insulin glargine or NPH insulin with existing regimens of one or two oral antidiabetic agents. This 24-week, randomized trial enrolled 756 patients. Although both basal insulins reduced FPG and HbA1c levels by similar amounts (FPG: $6.4 \mathrm{mmol} / \mathrm{L}$ versus $6.6 \mathrm{mmol} / \mathrm{L}$; HbA1c: $6.96 \%$ versus $6.97 \%$ for insulin glargine and NPH insulin, respectively), 25\% more patients attained a target HbA1c level of $=7 \%$ without experiencing nocturnal hypoglycemia with insulin glargine than with NPH insulin $(\mathrm{p}<0.05)$. The overall rate of hypoglycemia, rate of symptomatic events, and rate of confirmed events in the insulin glargine group were reduced by $21 \%, 29 \%$, and $41 \%$, respectively (15).Yki-Jarvinen's group designed a similar trial, but the treatment period was one year. Again, insulin glargine and NPH insulin reduced HbA1clevels by a similar amount, but there was less nocturnal hypoglycemia (9.9\% versus $24.0 \%$ of patients, $\mathrm{p}<0.001)$ and insulin glargine was associated with better post-meal glucose control than NPH insulin $(9.9 \mathrm{mmol} / \mathrm{L}$ versus $10.7 \mathrm{mmol} / \mathrm{L}, \mathrm{p}<$ $0.002)^{(16) \text {. }}$

While some studies have shown similar rates of hypoglycemia when compared with NPH insulin, there is also evidence insulin glargine can maintain effective glucose control and reduce risk of hypoglycemia. Rosenstock et al (2001) randomized 518 patients with type 2 diabetes, who were already being treated with basal NPH insulin and regular insulin, to receive either insulin glargine or NPH insulin once- or twice daily. While improvements in HbA1c were comparable, the group who switched to insulin glargine showed a $25 \%$ decrease in the rate of nocturnal hypoglycemia (26.5\% versus $35.5 \%, \mathrm{p}=0.0136)$. A recent meta analysis of four openlabel, randomized trials of insulin glargine versus NPH insulin adds further weight to this assertion. In total, 2304 patients were randomized and while glycemic control was similar between groups, there was a significant and consistent reduction in the risk of hypoglycemia.(17)While in our study insulin glargine and human premix insulin both associated with significant reductions in fasting blood sugar and HbA1c but hypoglycaemia risk was lesser with insulin glargine.

Weight gain has long been an issue with insulin therapy. Insulin glargine has been associated with a mean weight gain of up to $2.02 \mathrm{~kg}$ in a 39 -month study of 239 patients being treated in combination with oral antidiabetic agents, but many studies have reported no significant weight gain despite significant improvements in HbA1c (18). Some evidence suggests that insulin glargine may be associated with less weight gain than NPH insulin. In two studies, NPH insulin was associated with significantly more weight gain than insulin glargine $(19,20)$. In a 16-week trial in patients with type 2 diabetes, weight gain was $0.4 \mathrm{~kg}$ with insulin glargine versus $1.4 \mathrm{~kg}$ with NPH insulin $(\mathrm{p}<0.0007){ }^{(17)}$. In contrast, one study reported similar gains in mean body weight following 1 year of treatment of patients with type 2 diabetes with insulin glargine $(+2.6 \mathrm{~kg}, \mathrm{n}=214)$ and NPH insulin $(+2.3 \mathrm{~kg}, \mathrm{n}=208)(16)$. While in our study weight gain was significantly higher with human premix insulin versus glargine: $1.4 \pm 0.02$ and $0.4 \pm 0.012$ $\operatorname{kg}(\mathrm{P}<0.0001)$. 
Case reports of nausea and vomiting in patients receiving insulin glargine have been published (21), although these adverse events are not seen in our study.

CONCLUSION: Managing diabetes with insulin is primarily based on the balance between the necessity of tight glycemic control and the risks associated with hypoglycemia. Insulin glargine appears to improve this balance such that at least equivalent glycemic control can be achieved with a lower risk of hypoglycemia than traditional basal insulins. In patients with type 2 diabetes, the reduced risk of hypoglycemia with insulin glargine, combined with the flexibility of once-daily dosing at any time of the day, is likely to make insulin a more acceptable option, which may mean that patients are more open to start insulin earlier and to intensify their insulin sooner. In the long-term this may lead to improvements in $\mathrm{HbA1c}$ and thereby a reduction in the long-term complications of diabetes. Insulin glargine treatment was associated with significantly less weight gain than NPH insulin treatment ( 0.40 vs. $1.40 \mathrm{~kg}$ ). Presumably, the difference in weight gain despite comparable improvement in glycemic control reflects the less frequent hypoglycemia seen with insulin glargine, the correction of which requires supplemental caloric intake.

\section{REFERENCES:}

1. Harris MI, Eastman RC, Cowie CC, Flegal KM, Eberhardt MS: Racial and ethnic differences in glycemic control in adults with type 2 diabetes. Diabetes Care 22: 403408, 1999

2. Turner RC, Cull CA, Frighi V, Holman RR, UK Prospective Diabetes Study Group: Glycemic control with diet, sulfonylurea, metformin, or insulin in patients with type 2 diabetes mellitus: progressive requirement for multiple therapies (UKPDS 49). JAMA 281: 2005-2012, 1999

3. Stratton IM, Adler AI, Neil HA, Matthews DR, Manley SE, Cull CA, et al: Association of glycemia with macrovascular and microvascular complications of type 2 diabetes (UKPDS 35): prospective observational study. BMJ 321: 405-411, 2000

4. Klein R, Klein BEK, Moss SE: Relation of glycemic control to diabetic microvascular complications of diabetes mellitus. Ann Intern Med 124:90-96, 1996

5. Hayward RA, Manning WG, Kaplan SH, Wagner EH, Greenfield S: Starting insulin therapy in patients with type 2 diabetes: effectiveness, complications, and resource utilization. JAMA 278: 1663-1669, 1997

6. Taskinen M-R, Sane T, Helve E, Karonen S-L, Nikkila EA, Yki-Jarvinen H: Bedtime insulin for suppression of overnight free fatty acid, blood glucose, and glucose production in NIDDM. Diabetes 38: 580-588, 1989

7. Riddle MC: Evening insulin strategy. Diabetes Care 13: 676-686, 1990

8. Shank ML, DelPrato S, DeFronzo RA: Bedtime insulin/daytime glipizide: effective therapy for sulfonylurea failures in NIDDM. Diabetes 44: 165-172, 1995

9. Bolli GB, Owens DR: Insulin glargine (Commentary). Lancet 356: 443-444, 2000

10. Rosenstock J, Schwartz SL, Clark CM Jr, Park GD, Donley DW, Edwards MB: Basal insulin therapy in type 2 diabetes: 28-week comparison of insulin glargine (HOE901) and NPH insulin. Diabetes Care 24: 631-636, 2001 
11. Bahr M, Kolter T, Seipke G, Eskel J. Growth promoting and metabolic activity of the human insulin analogue [GlyA21, ArgB31, ArgB32] insulin (HOE 901) in muscle cells. Eur J Pharmacol.1997; 320:259-65.

12. Owens DR, Coates PA, Luzio SD, Tinbergan JP, Kurzals R. Pharmacokinetics of 125Ilabeled insulin glargine (HOE 901) in healthy men: comparison with NPH insulin and the influence of different subcutaneous injection sites. Diabetes Care.2000; 23:813-19.

13. Heinemann L, Linkeschova R, Rave K, Hompesch R, Sedlak M, Heise T. Time-action profile of the long-acting insulin analog insulin glargine (HOE901) in comparison with those of NPH insulin and placebo. Diabetes Care.2000; 23:644-9.

14. Lepore M, Pampanelli S, Fanelli C, Porcellati F, Bortocci L, DiVincenjo A, et al. Pharmacokinetics and pharmacodynamics of subcutaneous injection of long-acting human insulin analog glargine, NPH insulin, and ultralente human insulin and continuous subcutaneous infusion of insulin lispro. Diabetes.2000; 49:2142-8.

15. Riddle MC, Rosenstock J, Gerich J. The treat-to-target trial: randomized addition of glargine or human NPH insulin to oral therapy of type 2 diabetic patients. Diabetes Care. 2003; 26:3080-6.

16. Yki-Jarvinen H, Dressler A, Ziemen M. Less nocturnal hypoglycemia and better postdinner glucose control with bedtime insulin glargine compared with bedtime NPH insulin during insulin combination therapy in type 2 diabetes. HOE 901/3002 Study Group. Diabetes Care.2000; 23:1130-6.

17. Rosenstock J, Schwartz SL, Clark CM Jr, Park GD, Donley DW, Edwards MB. Basal insulin therapy in type 2 diabetes: 28-week comparison of insulin glargine (HOE 901) and NPH insulin. Diabetes Care. 2001; 24:631-6.

18. Dunn CJ, Plosker GL, Keating GM, Mckeage K, Scott LJ. Insulin glargine: an updated review of its use in the management of diabetes mellitus. Drugs. 2003; 63:1743-78.

19. Raskin P, Klaff L, Bergenstal R, Halle JP, Donley D, Mecca T. A 16-week comparison of the novel insulin analog insulin glargine (HOE 901) and NPH human insulin used with insulin lispro in patients with type 1 diabetes. Diabetes Care. 2000; 23:1666-71.

20. Garg SK, Paul JM, Karsten JI, Menditto L, Gottlieb PA. Reduced severe hypoglycemia with insulin glargine in intensively treated adults with type 1 diabetes. Diabetes Technol Ther. 2004; 6:589-95.

21. Dixon AN, Bain SC. Nausea and vomiting due to insulin glargine in patient with type 1 diabetes mellitus. BMJ. 2005; 330:455.

Table 1: Baseline characteristics of subjects in the study 
ORIGINAL ARTICLE

\begin{tabular}{|l|l|l|}
\hline & Glargine & Human Premix Insulin \\
\hline Number & 370 & 380 \\
\hline Sex (F/M) (\%) & $58 / 42$ & $54 / 46$ \\
\hline Age (years) & $45 \pm 9.5$ & $46 \pm 8.9$ \\
\hline Duration of diabetes (years) & $10 \pm 5$ & $9.0 \pm 6$ \\
\hline BMI (kg/m²) & $31.8 \pm 3.63$ & $32.2 \pm 3.85$ \\
\hline FBG (mg/dl) & $188 \pm 39$ & $184 \pm 47$ \\
\hline HbA1c (\%) & $8.58 \pm 0.7$ & $8.46 \pm 0.8$ \\
\hline Prior therapy (\%) & & 27 \\
\hline SU + metformin & 24 & 73 \\
\hline SU + metformin+ TZD & 76 & \\
\hline
\end{tabular}

Table 2:- Weekly insulin titration Table

\begin{tabular}{|l|l|}
\hline \multicolumn{2}{|l|}{ Start with $10 \mathrm{IU} /$ day bedtime basal insulin and adjust weekly } \\
\hline FBG values & Increase of insulin dosage (IU) day \\
\hline$>180 \mathrm{mg} / \mathrm{dl}$ & 8 \\
\hline $141-180 \mathrm{mg} / \mathrm{dl}$ & 6 \\
\hline $121-140 \mathrm{mg} / \mathrm{dl}$ & 4 \\
\hline $101-120 \mathrm{mg} / \mathrm{dl}$ & 2 \\
\hline
\end{tabular}

Figure: A. Mean HbA1c variation during study

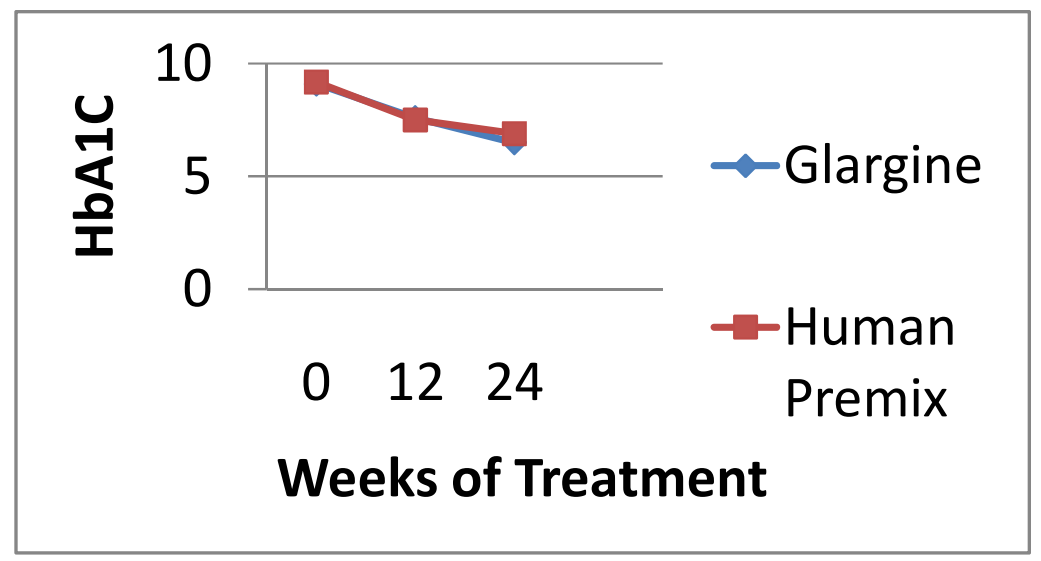

Figure: B. Mean Fasting blood Sugar during Study 


\section{ORIGINAL ARTICLE}

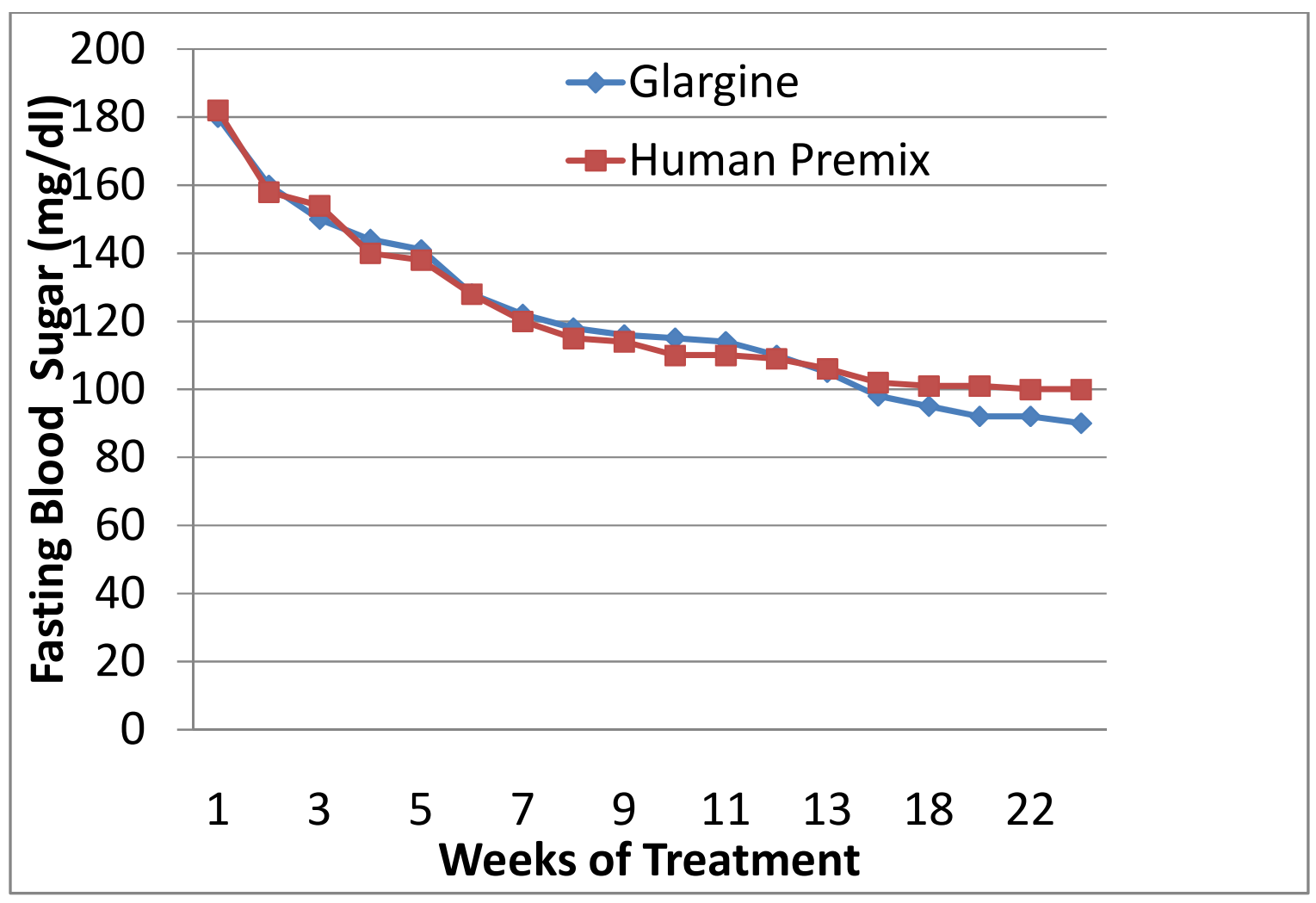

Figure: C. Mean daily insulin dose during study 


\section{ORIGINAL ARTICLE}

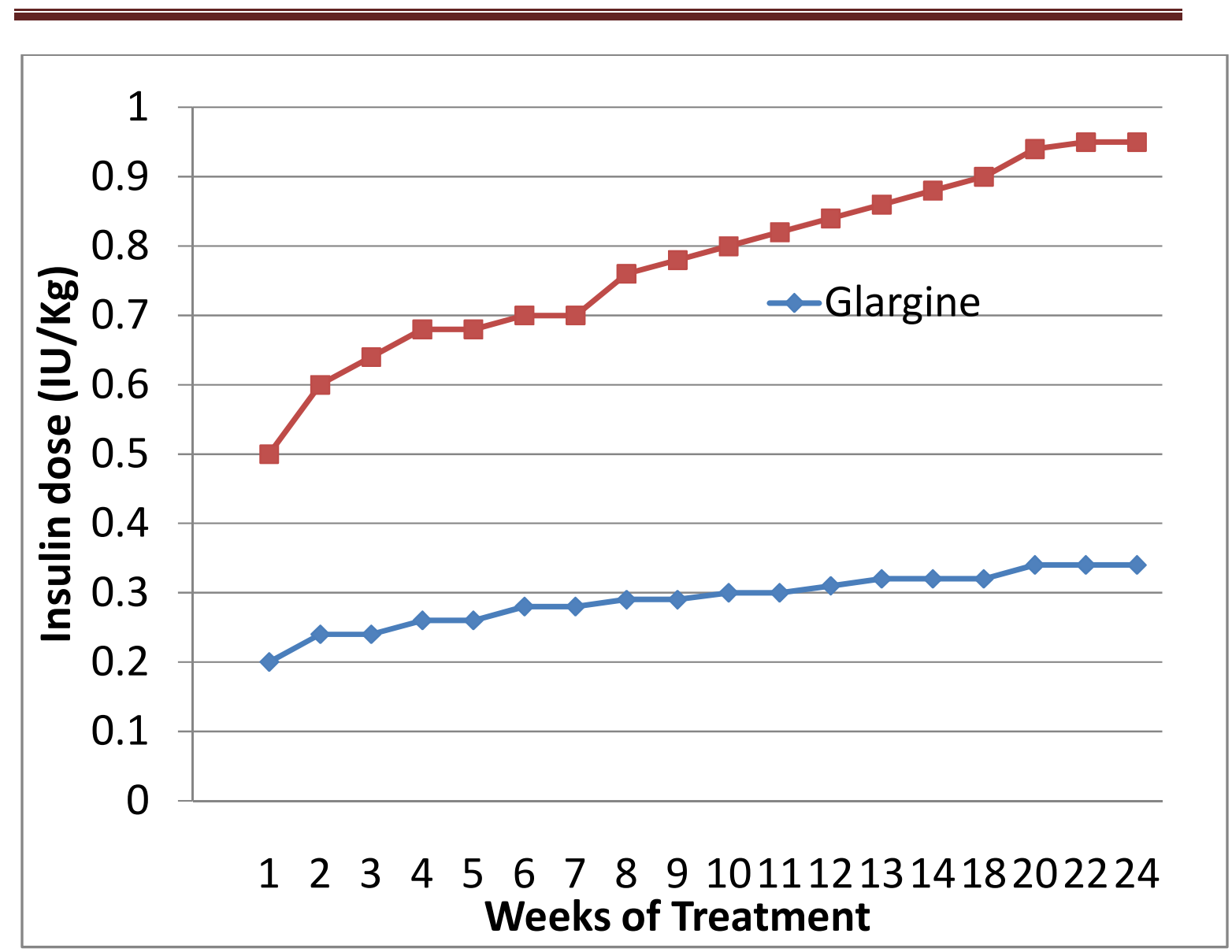

